Annuaire suisse de politique de développement

$11 \mid 1992$

Annuaire Suisse - Tiers Monde 1992

\title{
VI. Chronologie Suisse et internationale
}

\section{(2) OpenEdition}

1 Journals

Édition électronique

URL : http://journals.openedition.org/aspd/1558

DOI : 10.4000/aspd.1558

ISSN : 1663-9669

Éditeur

Institut de hautes études internationales et du développement

\section{Édition imprimée}

Date de publication : 1 janvier 1992

Pagination : 150-156

ISSN : 1660-5934

\section{Référence électronique}

"VI. Chronologie Suisse et internationale », Annuaire suisse de politique de développement [En ligne], 11 |

1992, mis en ligne le 18 mai 2013, consulté le 08 septembre 2020. URL : http:// journals.openedition.org/aspd/1558; DOI : https://doi.org/10.4000/aspd.1558

(c) The Graduate Institute I Geneva 


\section{Chronologie Suisse et internationale}

\section{Août 1990}

6 Août

Le Secrétaire d'Etat Jacobi (OFAEE) mène des discussions en Thaïlande en vue d'un accord pour la protection des investissements.

7 août

Suite à l'occupation du Koweït par les troupes irakiennes, la Suisse adopte des sanctions économiques contre l'Irak.

\section{Septembre 1990}

3-8 septembre

BIE, Bureau international de l'éducation, 42e session de la Conférence internationale de l'éducation à Genève, sur le thème de l'alphabétisation.

\section{3-14 septembre}

CNUCED, Conférence des Nations Unies sur les pays les moins avancés, Paris.

\section{4 septembre}

Conférence annuelle de la DDA sur le thème des "migrations dans le Tiers Monde et le rôle de la coopération au développement", Berne.

10-14 septembre

Session du Conseil international du cacao à Londres.

19 septembre

Ouverture de la 45e Assemblée générale des Nations-Unies, New York. 
19 septembre

Le Conseil national accepte le $4 \mathrm{e}$ crédit-cadre pour la poursuite de la coopération technique et de l'aide financière en faveur des pays en développement.

23-25 septembre

Assemblée annuelle du FMI et de la Banque mondiale, Washington.

29-30 septembre

UNICEF, Sommet mondial pour les enfants, New York.

\section{Octobre 1990}

\section{1-12 octobre}

CNUCED, première partie de la 37 e session du Conseil du commerce et du développement, Genève.

\section{3 octobre}

Le Conseil des Etats accepte le 4e crédit-cadre pour la continuation des mesures de politique économique et commerciale.

\section{9-14 octobre}

Le Conseiller fédéral Felber se rend à Madagascar, l'un des pays de concentration de l'aide publique au développement.

16 octobre

Journée mondiale de l'alimentation. Des actions ont lieu en Suisse sur le thème de la diversité génétique.

29 octobre-7 novembre

2e Conférence mondiale sur le climat, Genève.

29 octobre- 9 novembre

OMPI, 8 e session du Comité d'experts sur l'harmonisation de certaines dispositions des législations protégeant les inventions, Genève.

\section{Novembre 1990}

\section{3-29 novembre}

Ville de Bienne, Atelier Cuba, cycles de films et manifestations culturelles, Bienne.

\section{2-20 novembre}

CNUCED, 14e session de la Commission des produits de base, Genève. 
26 novembre- 7 décembre

Deuxième Conférence des Nations Unies chargée de revoir l'Ensemble de principes et de règles convenus au niveau multilatéral pour le contrôle des pratiques commerciales restrictives, Genève.

\section{Décembre 1990}

\section{3-7 décembre}

GATT, réunion ministérielle de Bruxelles, qui devait marquer la clôture des négociations de l'Uruguay Round. Les négociations sont prolongées, compte-tenu des divergences qui subsistent encore sur certains dossiers.

\section{Janvier 1991}

\section{Février 1991}

Les représentants de 12 nations ou peuples fondent l'organisation des populations non représentées (Unrepresented Nations and Peoples Organization, Unpo), pour faire mieux connaître les peuples non représentés aux Nations Unies sur le plan international.

\section{Mars 1991}

\section{4-19 mars}

Conférence pour la révision de la Convention internationale de protection des obtentions végétales (UPOV), Genève.

\section{8 mars}

Création de la Fondation de l'Académie suisse pour le développement, avec siège à Berne, à l'Institut pour l'analyse du développement et des pratiques de l'intervention. Le premier programme de recherche est axé sur les problèmes des migrations/ conflits culturels.

\section{1-22 mars}

CNUCED, deuxième partie de la 37 e session du Conseil du commerce et du développement, Genève.

\section{1 mars-7 avril}

Une délégation menée par le Conseiller fédéral Jean-Pascal Delamuraz se rend en visite en Corée du Sud et Singapour. 


\section{Avril 1991}

2-6 avril

Le Conseiller fédéral René Felber se rend en Iran et en Turquie.

8-13 avril

Rencontres Médias Nord-Sud (RMNS), Genève et Sion.

10 avril

La Suisse signe la Convention des droits de l'enfant qui date du 20 novembre 1989.

12 avril

La Suisse et l'Argentine signent un accord sur la protection des investissements.

22-30 avril

CNUCED, 8e session de la Commission du transfert de technologie, Genève.

\section{Mal 1991}

6-16 mai

OMS, 44e Assemblée mondiale de la santé, Genève.

Juin 1991

2-21 juin

OMPI, première partie de la Conférence diplomatique pour la conclusion d'un traité complétant la Convention de Paris en ce qui concerne les brevets, La Haye, Pays-bas.

\section{5-26 Juin}

OIT, 78e session de la Conférence internationale du travail, Genève.

10 juin

Le Conseil Fédéral présente son Message pour le crédit-cadre de 1"050 millions de francs pour la continuation de l'aide humanitaire (1992-1996).

18 juin

Le Conseil des Etats accepte l'adhésion de la Suisse au FMI et à la Banque Mondiale. 
24 juin

Inauguration de l'accadémie internationale de l'environnement, Genève.

\section{Juillet 1991}

15-17 juillet

Sommet mondial des 7 pays les plus industrialisés (G7) et de la Communauté européenne, Londres. Des manisfestations alternatives ont lieu au même moment, dont «the Other Economic Summit".

\section{Août 1991}

19-22 août

Symposium international à Disentis, dans le cadre des festivités du 700e anniversaire de la Confédération, sur le thème: "A qui appartient le monde? Le Nord et le Sud en dialogue".

22-24 août

Réunion internationale sur la banane, organisée par la Gebana, Zurich

26-30 août

Premier sommet mondial des femmes, Genève

\section{Septembre 1991}

\section{3-19 septembre}

Conférence sur le Programme d'action des Nations-Unies pour le redressement économique de l'Afrique, dans le cadre de l'Assemblée générale des Nations-Unies.

\section{4 septembre}

La Suisse accorde un crédit mixte de 60 millions de francs à l'Egypte (constitué pour moitié par un don de la Confédération et pour l'autre moitié par des crédits bancaires).

\section{5 septembre}

Conférence annuelle de la DDA sur le thème de la recherche et le transfert de technologie dans la coopération au développement.

\section{6-13 septembre}

Session du Conseil international du cacao, Londres. 


\section{7 septembre}

Le Conseil National approuve l'adhésion de la Suisse au FMl et à la Banque Mondiale.

\section{8 septembre}

Le Conseil National approuve l'adhésion de la Suisse aux deux pactes des Nations-Unies sur les droits de l'homme de 1966. Le pacte I contient un catalogue des droits économiques, sociaux et culturels. Le pacte II garanti des droits fondamentaux et la liberté.

\section{9-20 septembre}

Symposium d'automne organisé par Swissaid sur le thème "Des plantes pour les hommes ou des brevets pour les firmes biotechnologiques?", Beme.

\section{3-27 septembre}

Réunion du Conseil international du café, Londres.

\section{3 septembre- 4 octobre}

CNUCED, première partie de la 38 e session du Conseil du commerce et du développement, Genève.

\section{7 septembre}

Le Conseil Fédéral présente le Message sur la continuation de la coopération avec les pays de l'Est et de l'Europe centrale pour un montant de 800 millions de francs.

\section{Octobre 1991}

1er octobre

Le Conseil des Etats accepte un crédit-cadre de 1"050 millions de francs pour la poursuite de l'aide humanitaire.

\section{8-14 octobre}

Le Conseiller Fédéral René Felber conduit des discussions en Inde sur la conclusion d'un accord de double imposition et de protection des investissements. II visite aussi des projets de développement soutenus par la Suisse.

\section{5-17 octobre}

Assemblée annuelle du FMI et de la Banque Mondiale, Bangkok/ Thaïlande.

\section{5 octobre-7 novembre}

Conférence générale de l'UNESCO, Paris. 
16 octobre

Journée mondiale de l'alimentation sur le thème "l'arbre, source de vie", et plusieurs manifestations sur le thème des biotechnologies.

\section{7 octobre}

Un Referendum contre l'adhésion de la Suisse au FMl et à la Banque Mondiale est lancé par des organisations de gauche, groupements de femmes et organisations tiers-mondistes.

\section{1 octobre}

Le plan mondial de protection de la Terre est lancé dans 65 pays, dont la Suisse, sous la coordination du PNUE, du WWF et de l'Union mondiale de la protection de la nature.

\section{5 octobre}

Un nouveau référendum est lancé contre l'adhésion de la Suisse au FMI, par des milieux politiques conservateurs. 